\title{
APORTACIONES PARA EL ANÁLISIS DE UN CLIMA LOCAL: VARIACIÓN ESTACIONAL DE LOS ESTADOS DEL CIELO EN BENIDORM ${ }^{1}$
}

\author{
Emilio Martínez Ibarra \\ Departamento de Análisis Geográfico Regional \\ Universidad de Alicante
}

\section{RESUMEN}

En el presente artículo se exponen una serie de ideas novedosas sobre el clima de la ciudad de Benidorm. Dada la carencia de fuentes analíticas fiables se han observado las condiciones atmosféricas imperantes en esta población durante más de 1.200 jornadas en el transcurso del periodo comprendido entre 1997-2002. Asimismo, el estudio se ha completado con el análisis del archivo retrospectivo de mapas de tiempo (de superficie y la topografía absoluta de $500 \mathrm{hPa}$ ) e imágenes de satélite 2 .

Palabras clave: Benidorm, observación, interpretación, estados del cielo y tipos sinópticos.

\section{ABSTRACT}

This article presents new ideas concerning the climate of the city of Benidorm. Due to the lack of reliable meteorological information, the author decided to observe the atmospheric conditions in this city for more than 1.200 days during the period 19972002. This study has been completed with the retrospective analysis of weather maps - surface maps and others with absolute topography of $500 \mathrm{hPa}$ - and satellite images.

Key words: Benidorm, observation, interpretation, states of sky and synoptic type.

1 El presente trabajo forma parte de la investigación doctoral que con el título «Clima y Turismo: análisis de la importancia de este factor natural para el desarrollo de los asentamientos y actividades turísticas en el litoral alicantino» lleva a cabo el autor, bajo la dirección del prof. Jorge Olcina Cantos en el seno del Departamento de Análisis Geográfico Regional de la Universidad de Alicante.

2 Esta fuente de información puede ser consultada en la siguiente dirección electrónica: www.infomet.fcr.es 


\section{Introducción}

Entre las deficiencias presentes en la «ociurbe» de Benidorm, ordenada y planificada fundamentalmente por y para el turismo, no así para la población que habitualmente reside en la misma, se encuentra la carencia de un observatorio meteorológico homologado por el Instituto Nacional de Meteorología; y ello, a pesar de las exigencias existentes en la actualidad en el segmento de la demanda turística, entre las cuales, como ya ha sido señalado por numerosos autores, no sólo se ha de incluir la diversificación de la oferta sino también una mayor calidad del producto ofertado. Precisamente, es en este último aspecto donde reside la necesidad de conocer con la mayor definición posible los recursos climáticos presentes en cualquier espacio turístico (GÓMEZ, 1999: 22).

Para poder afrontar el análisis del clima de Benidorm, bajo una óptica distinta a la habitual, dada la carencia señalada anteriormente, se ha optado por realizar anotaciones diarias de manera sistemática relativas a las características de la temperie a diferentes horas del día, es decir, antes del amanecer, en su defecto a lo largo de la mañana, primera mitad de la tarde y tras el ocaso, en ocasiones ampliadas a otros intervalos horarios si las situaciones meteorológicas, por su particular interés, lo requerían.

Entre las variables analizadas señalar, por ejemplo, el grado de cobertura nubosa del cielo, el tipo de nubosidad, la visibilidad, la precipitación horizontal y vertical (cantidad o intensidad, respectivamente), así como la presencia de nieblas en relieves, entre otras.

Con el objeto de mejorar y ampliar las referencias anotadas, ya que de la mera observación directa no siempre se percibe el contexto meteorológico general, esencial para poder interpretar el paisaje nubígeno presente, en aparente paradoja, a la escala de análisis, se ha analizado e interpretado los respectivos mapas de tiempo, de $500 \mathrm{mb}$ y de superficie, e imágenes de satélite del meteosat, a las $12 \mathrm{~h}$., y del NOAA —en éste último caso relativas a la primera mitad de la tarde $\mathrm{y}$, en ocasiones, de la madrugada—. Una vez cotejada toda esta información, esto es, 1.262 comentarios sobre la temperie, 2.524 mapas de tiempo y más de esta última cantidad de imágenes de satélite, se ha clasificado y codificado con el fin de crear una base de información compuesta por unos 85.000 datos simples, sin contabilizar el campo referido al tipo de tiempo ${ }^{3}$.

Posteriormente, a partir del cruce de la misma se ha procedido a su tratamiento, y, de esta forma, se ha establecido su dependencia con contextos meteorológicos determinados, así como las relaciones existentes entre variables (como, por ejemplo, el rocío y la visibilidad). De esta manera se puede analizar la información y, así, elaborar un extracto inteligible; esto es, una clasificación de tipos de tiempo con indicación de sus causas y características, y su evolución a lo largo de los diferentes periodos estacionales e, incluso, para algunos de ellos, a una resolución temporal horaria.

Así pues, se procede a analizar algunas de las particularidades que conforman la realidad meteorológica y climática de la ciudad turística que mejor caracteriza en el Estado Español el modelo Fordista de esta trascendental actividad económica a partir de un método poco convencional, aunque verdaderamente arduo, ya que, tal y como se ha indicado, no se dispone de la información de base elemental y, por consiguiente, ésta ha de ser creada.

\section{Contexto geográfico-atmosférico general}

La ciudad de Benidorm se sitúa a $38^{\circ} 32^{\prime}$ de latitud y $00^{\circ} 08^{\prime}$ de longitud oeste; posición periférica meridional respecto a la Península Ibérica y la circulación atmosférica

3 Difícilmente se hubiera podido interpretar toda esta información si no se hubiera proyectado a un código de presencia o ausencia, y otro de carácter más complejo para calificar los tipos de tiempo. 
que impone el vórtice circumpolar en las latitudes medias. Este enclave «marginal» determina que el abrigo aerológico subtropical adquiera verdadera significación, así como el orográfico. En relación a este último, destaca el papel ejercido por la Península Ibérica en la reducción de las precipitaciones que aportan las ondas baroclínicas ligadas a borrascas extratropicales con estructura frontal en el área mediterránea peninsular, tras su habitual desplazamiento zonal; merma pluviométrica acentuada por la presencia del continente africano, en relación con los vientos del tercer cuadrante, y, muy especialmente, por las cordilleras Béticas.

En definitiva, la localización del espacio objeto de estudio en el borde meridional de la circulación atmosférica que domina las latitudes medias, y a sotavento de ésta, determina unos totales pluviométricos escasos al ser las circulaciones menos frecuentes en superficie, inversas, las que pueden aportar cantidades importantes - gravamen incrementado por la aleatoriedad e irregularidad de las mismas - . No obstante, y precisamente por lo señalado con anterioridad, las horas de sol son muy abundantes y las temperaturas «suaves», ambos recursos climáticos imprescindibles para el desarrollo del turismo de masas por excelencia.

\section{El clima local de Benidorm}

Con carácter general, el clima de este sector peninsular es mediterráneo de fachada oriental, a caballo entre los climas templados y tropicales, por tanto, subtropical. Dos son las variables que mejor lo definen. Por un lado, la escasez e irregularidad de las precipitaciones, con predominio de los ciclos secos frente a los húmedos, con la consiguiente elevada insolación, en torno a las 2.800 horas anuales, y, de otro, la suavidad de sus registros térmicos, manifiesta en el periodo invernal ${ }^{4}$, pero no así, como temperatura eficaz, durante el periodo canicular por la elevada humedad reinante.

Ciñéndonos más en el espacio objeto de estudio, la ciudad de Benidorm se emplaza en el noreste de la provincia de Alicante bajo la protección impuesta por una orla de relieves que únicamente presentan solución de continuidad al mediodía. A priori, emplazamiento geográfico-climático ideal (vid. Mapa 1). En efecto, así ha sido reflejado por algunos autores que apuntan para Benidorm una temperatura media de $19^{\circ} \mathrm{C}$, e incluso algo superior, la más elevada de la Comunidad Valenciana ${ }^{5}$ y no alcanzada por ninguna otra capital litoral de la Península Ibérica. No obstante, ese valor a «todas luces» se halla sobrevalorado ya que si la capital más templada del territorio peninsular (Almería), con $18,7^{\circ} \mathrm{C}$ de temperatura media anual, debe sus valores suaves a los elevados registros alcanzados por las mínimas diarias ${ }^{6}$, este hecho en modo alguno resulta similar en Benidorm, fundamentalmente por su mayor latitud ${ }^{7}$.

4 «(..) en levante, el invierno, más que como estación meteorológica bien definida, se manifiesta de forma esporádica e irregular (...)» (FONT, 2000: 256).

5 «No es difícil comprobar que la temperatura de las tierras valencianas aumenta de oeste a este y de norte a sur. Si nos referimos a medias anuales, los extremos se sitúan en Sant Joan de Penyagolosa, observatorio situado a $1300 \mathrm{~m}$. de altitud, que da $9^{\circ}$ escasos, y en Benidorm, tocando el mar y expuesto a medio día, con 19,6²» (ROSELLÓ, 1995: 68).

6 Según los datos del I.N.M. en el observatorio meteorológico de esta capital andaluza las temperaturas nunca han quedado por debajo de $\operatorname{los} 0^{\circ} \mathrm{C}$. En cambio, en Benidorm aunque estos registros resulten excepcionales si se han anotado.

7 Incluso la protección ante advecciones del norte se ve en este sector andaluz acentuada por la presencia de los relieves penibéticos, indudablemente más elevados y con mayor desarrollo latitudinal que las sierras del Prebético Externo. 


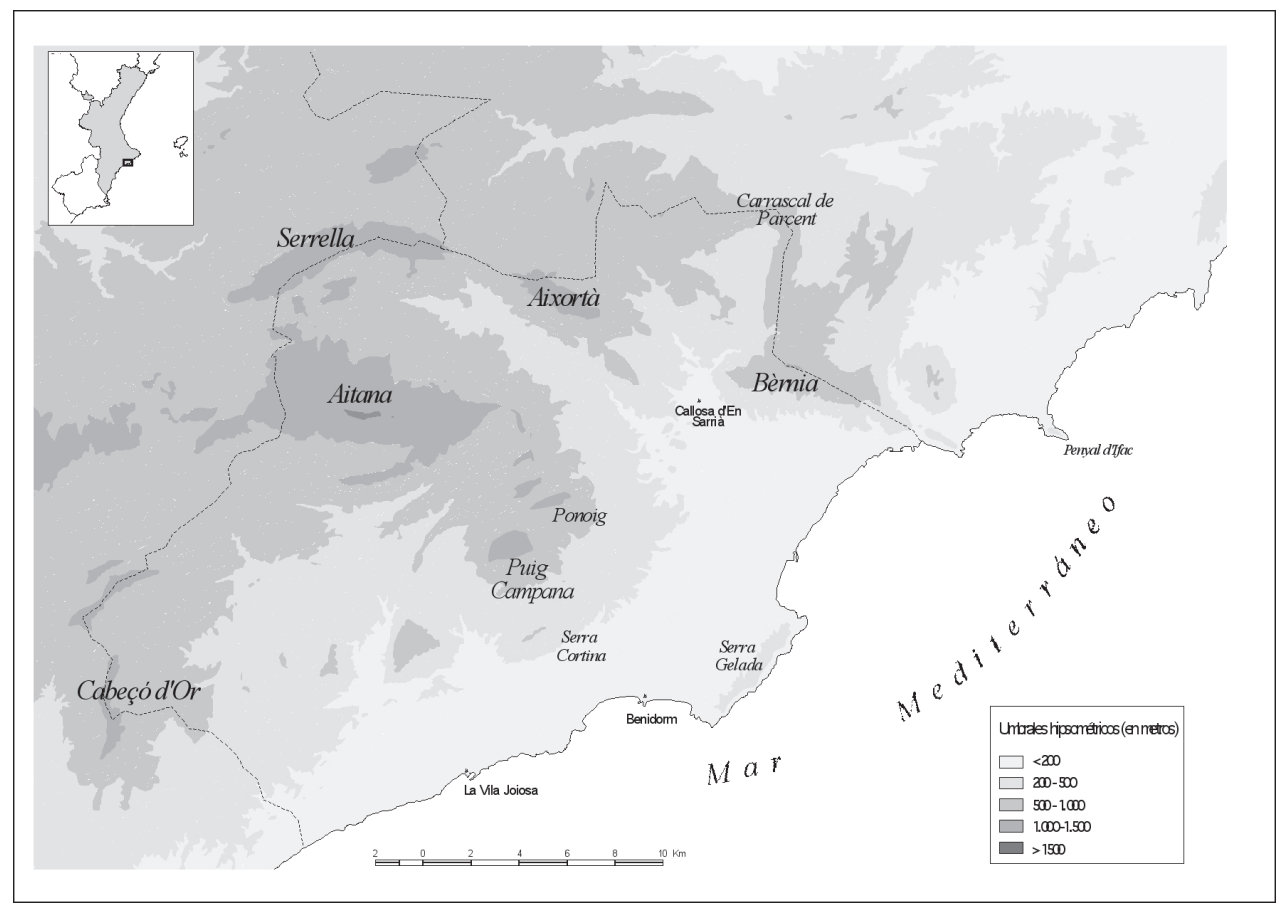

MAPA 1. Contexto topográfico del área objeto de estudio ${ }^{8}$.

De hecho, así lo corroboran las observaciones realizadas y, más aún, la existencia del topónimo Serra Gelada. En efecto, la denominación de este relieve atribuye a este accidente orográfico la génesis de heladas ${ }^{9}, \mathrm{o}$, mejor dicho, escarchas, al menos en la actualidad, en la depresión presente a sus pies, en relación con la falla que limita el monoclinal fallado de esta cresta por el NW (Vid. Foto 2) ${ }^{10}$.

Asimismo, esa protección que a escala local, e incluso regional, ejercen los relieves ha de ser matizada. Al parecer, todo parece indicar, que ésta es máxima con vientos del tercer cuadrante, que por otro lado resultan bastantes frecuentes, ya que la relacionada con vientos de levante se restringe, al menos de forma eficaz, al sector más oriental de la Playa de Levante. Respecto a los flujos de procedencia NE señalar que la Serra de Bèrnia no protege de forma sustancial de esta componente a Benidorm, desde un punto de vista de la fuerza del viento ${ }^{11}$. Además, otros 2 factores podrían inhibir aún más su protección: en

\footnotetext{
8 Agradezco la inestimable colaboración prestada por Ángel Sanchez Pardo en la elaboración de este

9 «El documento de 1781 en el que aparece la Sierra dha. La Elada nos da el significado del topónimo. Es decir, la climatología que genera la sierra, como efectivamente es» (ALMIÑANA, 2001: 176).

$10 \mathrm{Ni}$ que decir tiene que este hidrometeoro se presenta de forma puntual, especialmente en el entorno «rural» (alejado de la isla de calor urbana y de la mayor influencia dulcificadora del mar), aunque con relativa frecuencia en el centro del invierno.

11 La localidad de Benidorm se sitúa en el extremo Este del posible abrigo aerológico que puedan ejercer los relieves del norte de Alicante frente a esta componente, y a una distancia considerable de la Serra de Bèrnia.
} mapa. 


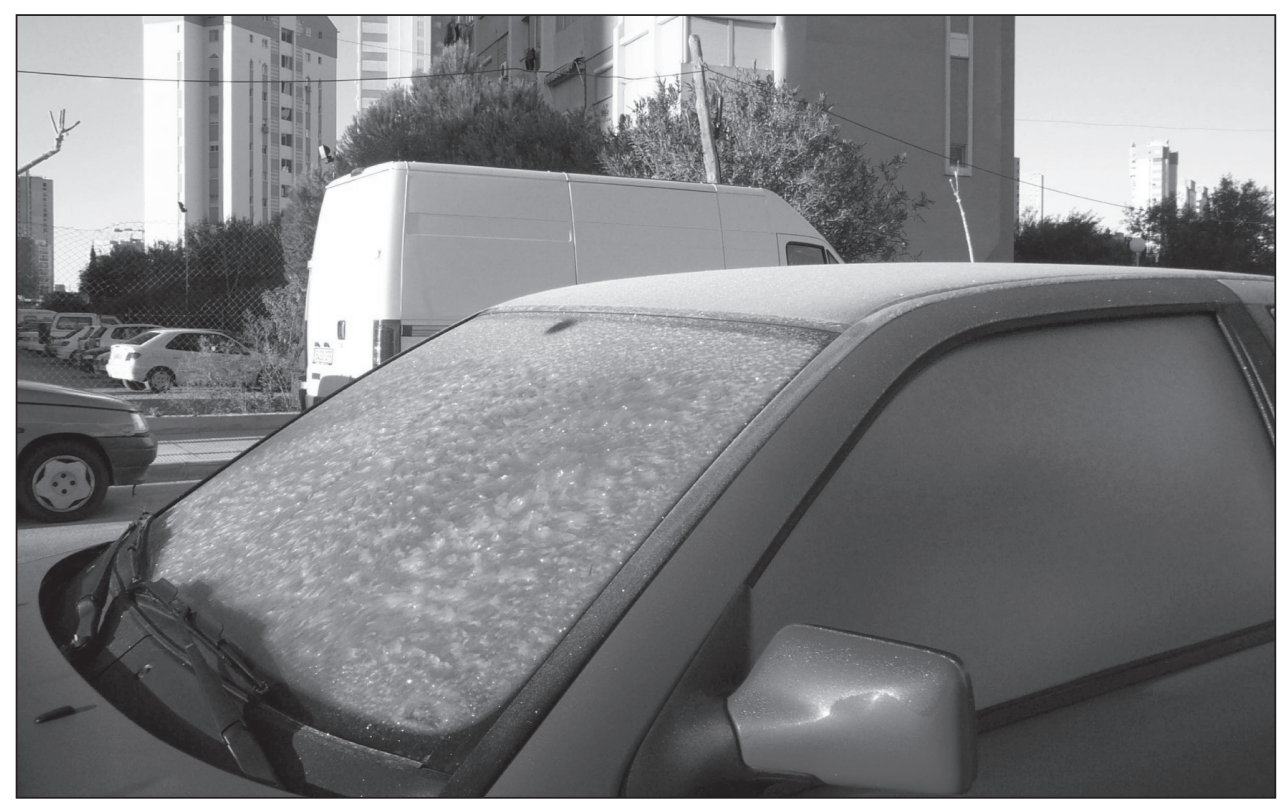

Fото 2. Escarcha sobre un vehículo en las afueras del ensanche de Levante de Benidorm, el sector de la ciudad más favorable para la precipitación de este tipo de meteoro ( mañana del 4 de enero de 2004, Calle Fuster Zaragoza).

primer lugar, la apertura a su influencia por el mal denominado Sinclinal de la Marina y la convergencia de este flujo con el que traspasa la Serra de Bèrnia (confluencia de flujos y energía). Por otro lado, respecto a las advecciones del SW señalar que éstas arriban a Benidorm sin ninguna protección a escala local.

Llegado a este momento, deberíamos interrogarnos sobre las repercusiones, que desde un punto de vista termométrico, pudiesen derivarse de la protección ante vientos de dirección NW-SE. En principio, la menor turbulencia incrementaría las oscilaciones diarias, siempre que el amparo resultase eficaz. Este último aspecto si se ha comprobado en alguna ocasión, constituyendo un ejemplo prototípico la situación del 1 de febrero de 2003 en la que llegó a helar al menos en el extremo nororiental de la ciudad de Benidorm, registrándose unos $-2^{\circ} \mathrm{C}$ (posiblemente, en aparente paradoja, la temperatura más baja alcanzada en la costa española durante ese año).

Asimismo, si analizamos los valores de las medias de las temperaturas máximas diarias (Vid. Cuadro 4) observaremos como éstas también resultan elevadas, muy especialmente en verano, como si la influencia «dulcificadora» de la brisa marina, desde un punto de vista térmico, no sensible, dejase a este sector de la provincia fuera de su influencia. En este sentido, podemos afirmar, por algunas observaciones realizadas, que ni si quiera se pueden explicar estas diferencias en el supuesto de que el viento dominante en estío fuera de componente este y, por tanto, Benidorm quedara bajo el amparo relativo ejercido por la Serra Gelada.

Desde un punto de vista pluviométrico, la protección resulta muy efectiva en relación a los vientos terrales y, en menor medida, respecto al gregal. No obstante, ésta (con ocasión de vientos del NE) es aún más manifiesta en La Vila Joiosa y en el resto del litoral sur provincial, dada la mayor proximidad de Benidorm al área más interesada pluviometricamente por este tipo de tiempo. 
CuAdro 4. Valores termométricos medios

\begin{tabular}{|c|c|c|c|c|c|c|}
\hline \multirow{2}{*}{ MESES } & \multicolumn{2}{|c|}{ Alicante } & \multicolumn{2}{c|}{ Almería } & \multicolumn{2}{c|}{ Benidorm } \\
\cline { 2 - 7 } & Max. & Min. & Max. & Min. & Max. & Min. \\
\hline ENE & 16,8 & 6,2 & 16,9 & 8,2 & 17,1 & 7,5 \\
\hline FEB & 17,8 & 7 & 17,7 & 8,8 & 17,9 & 7,6 \\
\hline MAR & 19,2 & 8,2 & 19,2 & 10,1 & 19,4 & 9,5 \\
\hline ABR & 20,9 & 10,1 & 21 & 11,9 & 23,4 & 12,7 \\
\hline MAY & 23,6 & 13,3 & 23,6 & 14,6 & 25,9 & 15,5 \\
\hline JUN & 27,2 & 17,1 & 27,3 & 18,2 & 29,6 & 19,2 \\
\hline JUL & 30,1 & 19,7 & 30,3 & 21,1 & 33,2 & 22,2 \\
\hline AGO & 30,6 & 20,4 & 30,7 & 22 & 33,2 & 22,1 \\
\hline SEP & 28,4 & 17,8 & 28,3 & 19,6 & 31,3 & 20,3 \\
\hline OCT & 24,4 & 13,7 & 24,3 & 15,7 & 26,5 & 16,2 \\
\hline NOV & 20,4 & 10 & 20,4 & 12 & 22,2 & 12 \\
\hline DIC & 17,6 & 7,3 & 17,9 & 9,4 & 18,4 & 8,3 \\
\hline MEDIA & \multicolumn{2}{|l|}{17,8} & 18,7 & & 19,3 \\
\hline
\end{tabular}

Fuente: I.N.M. y QUEREDA, $(1978)^{12}$.

De otro lado, respecto a la intensidad de los temporales marítimos, dado que el litoral de la ciudad de Benidorm presenta una disposición general oeste-este se halla muy bien resguardada ante temporales del NE y, en menor medida, respecto a los levantes (únicamente los extremos orientales de las dos playas que conforman la línea costera de su núcleo urbano manifiestan una protección eficaz). En cambio, las advecciones del S, SSW y SW ejercen su influencia prácticamente en la totalidad de la costa benidormí, tanto más cuanto más se aproxime la dirección del flujo a los $180^{\circ}$, quedando protegida sólo la Cala de Benidorm.

\subsection{Otras variables atmosféricas de interés}

Otros elementos meteorológicos de interés, algunos de ellos escasamente analizados en los estudios de climatología, son: cobertura nubosa, tipo e intensidad de las precipitaciones, nieblas en los relieves circundantes del espacio analizado, precipitaciones horizontales ocultas (rocíos) o la visibilidad.

En Benidorm, durante el periodo analizado, han predominado ampliamente las jornadas con cielos casi despejados o poco nubosos (con el 64,34\% de los casos analizados), frente a los días nubosos (que han representado el 27,89\%), o cubiertos o casi cubiertos (que han constituido el 7,77\%); con contrastes importantes en relación con los relieves que la

12 Los valores termométricos de Alicante y Almería corresponden al periodo 1971-2000 recogidos por el I.N.M. y los de Benidorm a las reducciones efectuadas por Quereda Sala con datos de 1960 a 1963. 
rodean, frecuentemente envueltos por la niebla, al menos durante 570 jornadas, especialmente durante el periodo tardo-estival, coincidiendo con elevados valores de tensión parcial de vapor de agua y humedad relativa.

Los tipos de tiempo más representativos se han correspondido con días despejados o casi despejados $(25,85 \%)^{13}$, líneas de discontinuidad frontal ligadas a borrascas extratropicales $(15,16 \%)$, flujos de componente mediterránea $(14,76 \%)$ y nubosidad acumulada por el virazón $(7,93 \%)^{14}$ (Vid. Cuadro 3). Desde un punto de vista atmosférico han dominado las masas de aire de origen polar $(64,10 \%)$, aunque han prevalecido las ondas baroclínicas de influjo secundario o circulaciones zonales $(46,20 \%)$ frente a los valles planetarios que afectan de lleno a la zona. Más concretamente, los escenarios sinópticos más representativos se han correspondido con vaguadas de influencia indirecta al oeste del mediterráneo y crestas mediterráneas (con un 26,10\% en ambas ocasiones).

Por otro lado, en contra de los tópicos del clima mediterráneo ${ }^{15}$, las precipitaciones registradas en Benidorm durante el periodo analizado ha venido caracterizadas por la escasa cantidad de lluvia registrada en las mismas (en 212 ocasiones de los 319 días con precipitación analizados). No obstante, es manifiesta la frecuencia de las precipitaciones moderadas y ocasionalmente intensas (107 ocasiones en total $)^{16}$.

En el trabajo realizado, se ha advertido que los tipos de tiempo más frecuentes durante éstas jornadas con precipitación han correspondido a situaciones caracterizadas por la presencia de frentes activos $(14,73 \%)$, gregales con precipitación (12,23\%), nubes de desarrollo vertical con precipitación en el litoral $(11,91 \%)$, frentes poco activos $(10,66 \%)$, norestes con escasa precipitación $(9,72 \%)$, levantes con escasa precipitación $(9,09 \%)$ y levantes con precipitación $(8,78 \%)$. Los tipos de tiempo potencialmente capaces de generar precipitación significativa e intensidades intensas (temporales de gregal y levante o nubes de desarrollo vertical de evolución diurna con precipitaciones generalizadas) sólo representan el 32,91\% de las jornadas en la que se han analizado días con lluvia, principalmente con vientos procedentes del mediterráneo, especialmente con flujos de componente NE $(36,45 \%$ de los casos frente al $26,17 \%$ correspondientes a advecciones del este o sureste), seguidos por episodios de precipitación ligados a la génesis de nubes de desarrollo vertical con precipitaciones generalizadas $(19,83 \%)$. En cambio, las lluvias poco importantes se han registrado principalmente con norestes con escasa precipitación $(21,22 \%)$, levantes con escasa precipitación $(16,51 \%)$, frentes fríos poco activos $(16,04 \%)$, frentes fríos activos $(15,57 \%)$ y nubes de desarrollo vertical con precipitación en el ámbito litoral $(8,02 \%)$.

De otro lado, el rocío y la visibilidad son otras variables que pueden resultar de interés en un estudio climático.

Respecto a los fenómenos de condensación pelicular en estado líquido señalar su vocación estacional por el periodo «frío» del año, coincidiendo con los valores termométri-

13 Este porcentaje se halla infravalorado, especialmente durante el periodo estival, por la presencia de tipos de tiempo que se traducen en cielos con escasa nubosidad durante el día, como por ejemplo las nieblas altas «nocturnas».

14 Para calcular los valores porcentuales se ha considerado oportuno tomar como referencia los días analizados por mes sin tener en cuenta el total de los días estudiados para así reflejar mejor la sucesión estacional de los tipos de tiempo y de esta forma corregir las deficiencias presentes por el mayor número de días considerados durante primavera.

15 «En Alacant plou poc, però quan plou, plou prou» (RAMÓN, 1992: 172).

16 «En la vertiente mediterránea, la baja frecuencia de días de precipitación y su reducida intensidad no impide eventos excepcionales (...)» (RASILLA ÁLVAREZ, D.F., 2003: 39). 
cos más bajos y el segundo máximo anual de días despejados o casi despejados. A este respecto, la caída del rocío en Benidorm, y, por ende, en gran parte del litoral mediterráneo, va ligada a noches con escasa nubosidad con viento en calma y cuerpos de aire que han adquirido por el influjo de la brisa marina, o la influencia de flujos marítimos de origen sinóptico, rasgos higrométricos derivados de su contacto con la cuenca del Mar Mediterráneo. Por ello, a medida que la cantidad de precipitación oculta ha resultado mayor han predominado masas de aire capaces de retener más humedad en las capas bajas con cielos poco nubosos, es decir, las de origen subtropical. De esta forma, cuando la cantidad de agua precipitada ha sido poco importante las masas de aire de origen polar se han mostrado más frecuentes, con una recurrencia similar a las tropicales, aunque, siempre, en el primer caso, con amplio predominio de las situaciones menos inestables (surcos barométricos de influjo secundario y, muy especialmente, circulaciones zonales ${ }^{17}$ ). La situación sinóptica más favorable para la precipitación pelicular por fenómenos de «pared fría» se ha correspondido con masas de aire de raigambre subtropical, con eje en el litoral mediterráneo o mediterráneo occidental, en su vertiente continental; es decir, aire sahariano que ha perdido el carácter higrométrico originario por el contacto superficial de éste con la superficie marina $(19,23 \%$ en el total de las ocasiones analizadas en las que el rocío ha resultado muy escaso, el 19,29\% en las cuales éste ha sido poco importante, el $21,26 \%$ en las ocasiones con buen rocío y en el $38,71 \%$ en las que la precipitación horizontal ha resultado muy abundante).

Respecto a la visibilidad conviene señalar que ha predominado, sobremanera, la calificada como buena ${ }^{18}(52,95 \%$ de los 918 casos analizados) frente a la mala o muy mala $(25,14 \%)$. No obstante, si aunamos las jornadas con visibilidad regular a las de mala visibilidad prácticamente suponen la mitad de las situaciones estudiadas ${ }^{19}$. Asimismo, se aprecian diferencias estacionales que responden al diferente dinamismo del vórtice circumpolar.

En relación a los escenarios sinópticos ligados al grado de nitidez atmosférica se ha corroborado que tras el paso de un frente frío, normalmente en el seno de ondas baroclínicas que sitúan su eje sobre el litoral mediterráneo o el mediterráneo occidental, incluso durante el primer día de influjo de temperies dominadas por masas de aire de origen tropical marítimo, precisamente en las ocasiones en las cuales no se produce precipitación horizontal oculta, en el primer caso, o ésta resulta muy escasa, en el segundo, cuando la visibilidad ha sido buena. Por ello, durante las jornadas con mejor transparencia atmosférica han predominado las masas de aire de origen polar.

Al realizar un análisis más pormenorizado, se ha comprobado que las escenarios sinópticos que mejor representan una atmósfera más diáfana se corresponden con circulaciones zonales y vaguadas con eje en el litoral mediterráneo o mediterráneo occidental que afectan al área objeto de estudio de pleno; con el 18,63 y 18,27\%, respectivamente. Por otro lado, entre las masas de aire de origen subtropical han despuntado tanto las tropicales marítimas como las continentales, en aparente paradoja ${ }^{20}$, con el 10,07 y 9,47\%, en cada caso.

17 A ello habría que añadir que las vaguadas que sitúan su eje al oeste del litoral mediterráneo, a las $12 \mathrm{~h}$ UTC., en ocasiones no se traducen en una noche nubosa con viento ya que su arribada al litoral mediterráneo puede acontecer durante el periodo diurno.

18 Los diferentes grados de diafanidad atmosférica se han clasificado a partir de la transparencia atmosférica reinante entre Benidorm y las sierras de Carrascal de Parcent y de Bèrnia.

19 Al haberse analizado un porcentaje similar durante las 4 estaciones que componen el año los datos pueden considerarse válidos.

20 Quizás resulte necesario recordar que en ocasiones la visibilidad, en superficie, resulta buena con este tipo de masas de aire cuando éstas no se muestran desnaturalizadas por el mar mediterráneo, especialmente con las de origen marítimo. 
En cambio, durante los días en los cuales la visibilidad se ha visto reducida de forma más o menos importante han predominado las temperies caracterizadas por el influjo subtropical (en el 52,24\% de las ocasiones cuando ésta ha resultado regular, en el 56,95\% de las situaciones con mala visibilidad y en el 59,09\% de los casos analizados con muy mala visibilidad). En este sentido, el contexto sinóptico dominante cuando la atmósfera se ha mostrado más opaca se ha correspondido con el dominio de advecciones saharianas, más concretamente crestas que sitúan su eje sobre el litoral mediterráneo o el mediterráneo occidental (en el 21,08\% cuando la transparencia atmosférica ha resultado regular, en el $29,14 \%$, ocasión de que ésta se halla mostrado mala y en el $28,79 \%$ de las ocasiones con visibilidad muy mala). Ante estas condiciones de transparencia atmosférica las masas de aire que con mayor asiduidad han caracterizado el cuadro sinóptico han sido las que sitúan su ramal ascendente sobre el espacio objeto de estudio con influencia indirecta y las circulaciones zonales ${ }^{21}$, con valores medios de $16,83 \%$ y $12,05 \%$, respectivamente.

La calima alta es otra de las variables a considerar en un estudio de climatología. Del análisis de 69 casos se ha desprendido que durante estas jornadas ha predominado, notoriamente, la influencia subtropical frente a la polar, $79,71 \%$ y $20,29 \%$ respectivamente, con una preponderancia abrumadora de las situaciones sinópticas marcadas por el influjo de crestas saharianas con eje ubicado en el litoral mediterráneo o mediterráneo occidental (66,67\% de total).

En definitiva, como ya se puede advertir, por lo enunciado en las líneas que anteceden a estas, existe una cierta relación entre visibilidad y precipitación horizontal oculta. No obstante, la correlación no es perfecta y se muestra más evidente en los extremos de ambas situaciones. Por ello, por un lado, ha dominado la buena visibilidad cuando el rocío es nulo o muy poco importante, y, de otro, la diafanidad atmosférica se ha mostrado regular o mala en aquellas jornadas en las que la precipitación horizontal oculta resultó «buena» o «muy buena».

\section{Situaciones sinópticas y estados del cielo en la ciudad de Benidorm y la comarca de la Marina Baixa}

\subsection{Tipos de tiempo distinguidos y características más significativas}

Es conveniente advertir que, por razones de espacio, únicamente se indica una relación de los tipos de tiempo fijados para el espacio objeto de estudio (Cuadro 1), aunque extrapolables a gran parte de la costa mediterránea peninsular, y las características que mejor definen a éstos (Cuadro 2).

Como se puede observar (vid. Cuadro 1) se han determinado 24 tipos de tiempo, algunos de los cuales se pueden establecer a partir de las referencias anotadas a escala local (como, por ejemplo, «este o norestes sin, con escasa o con lluvia», en ocasiones producto de la aparente distribución anárquica de la precipitaciones ante temporales de «levante»; «nubes de evolución prelitoral sin lluvia»; «nubosidad acumulada por brisa»; «nubes de evolución con lluvias generales»; etc.). En otras, en cambio, la observación únicamente ayuda a completar las situaciones distinguidas a partir de los medios de observación remota (nubes de evolución de interior o frentes poco activos). Asimismo, a veces, la

21 Durante estas jornadas el reflejo de la circulación zonal en altura no se ha manifestado en superficie ya que han predominado las situaciones de pantano barométrico. 
Cuadro 1. Tipos de tiempo establecidos con sus correspondientes códigos

\begin{tabular}{|l|c|}
\hline Tipos de tiempo & Código \\
\hline Despejado o casi despejado & 1 \\
\hline Frente poco activo & 2 \\
\hline Nubosidad acumulada por brisa & 3 \\
\hline Este sin lluvia & 4 \\
\hline Noreste sin lluvia & 5 \\
\hline Nieblas altas nocturnas & 6 \\
\hline Nubes de evolución con lluvias generales & 7 \\
\hline Frente frío activo & 8 \\
\hline Ondas de stratocumulus & 9 \\
\hline Nubosidad media y alta a sotavento & 10 \\
\hline Niebla alta & 11 \\
\hline Nubes de evolución en interior & 12 \\
\hline Noreste con lluvia & 13 \\
\hline Frente «africano» & 14 \\
\hline Este con lluvia & 15 \\
\hline Noreste con poca lluvia & 16 \\
\hline Este o Noreste con escasa humedad & 17 \\
\hline Nubes de evolución con escasa humedad & 18 \\
\hline Altocumulus «africanos» & 19 \\
\hline Nubes de evolución prelitoral sin lluvia & 20 \\
\hline Este con escasa lluvia & 21 \\
\hline Nubes de evolución con escasa humedad y lluvia & 22 \\
\hline Niebla & 23 \\
\hline Nubes de evolución de interior con lluvia & 24 \\
\hline Total casos analizados & 7 \\
\hline
\end{tabular}

Elaboración propia. 


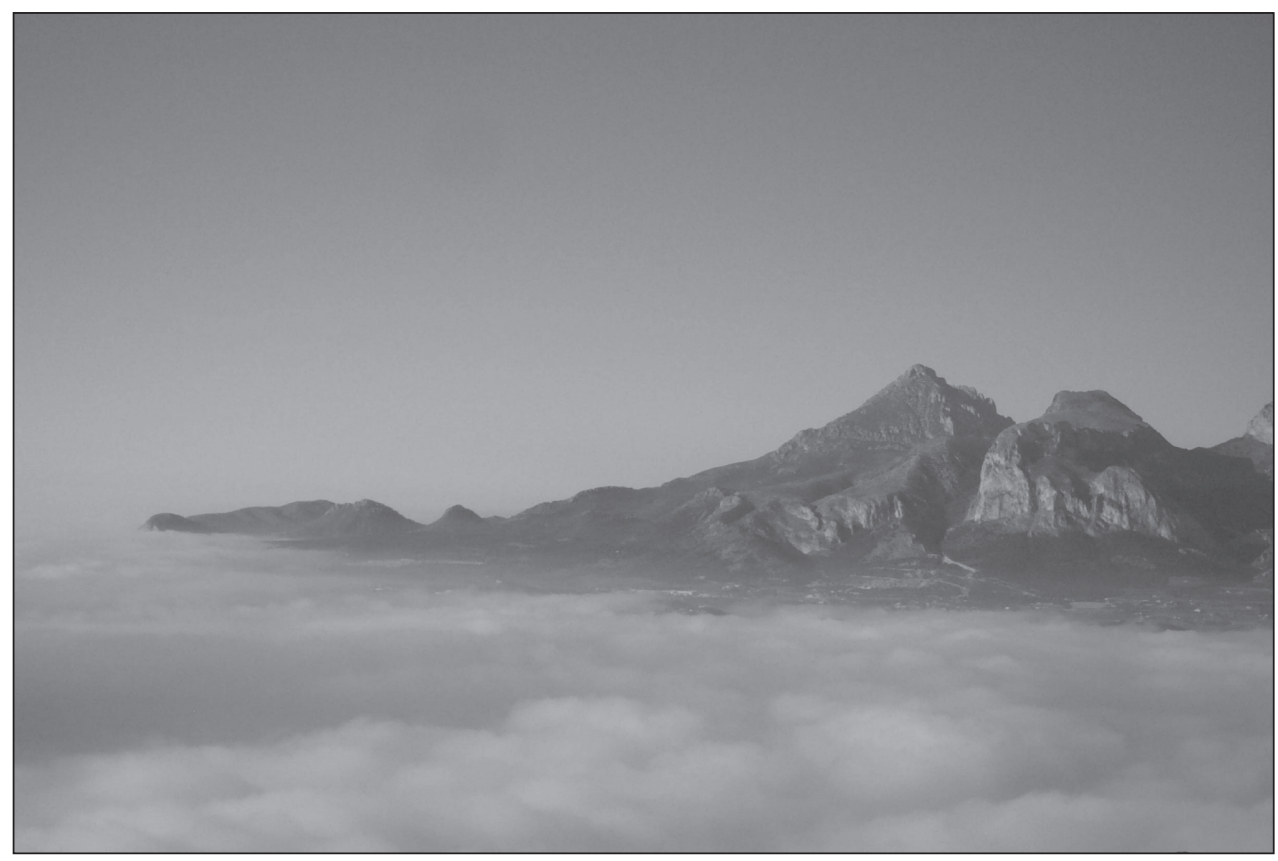

Fото 1. Situación típica de niebla alta de advección en la comarca de la Marina Baixa (7 de febrero de 2004, 10:20h. Vista del Ponoig y Puig Campana desde la Serra de Bèrnia.). Mientras la costa y parte del litoral aparecen bajo el manto de los stratos y una capa de neblina que dificulta la visibilidad sobremanera, a unos $300 \mathrm{~m}$. de altitud, tras el nivel de inversión, las condiciones se muestran francamente distintas, esto es, con cielo despejado, escasa humedad y buena visibilidad.

interpretación de las imágenes de satélite resulta indispensable, tal es el caso de los clasificados como «ondas de stratocumulus» o «nubosidad media y alta a sotavento», aunque también existen situaciones totalmente opuestas, es decir, en las que sin la observación hubiera resultado imposible su catalogación (por ejemplo, para el tipo denominado «nieblas altas nocturnas», o en la distinción que se establece entre «niebla alta» —Foto 2 o «niebla» en su sentido más original y restrictivo).

Además, conviene tener presente que dada la afinidad existente entre algunos de los tipos de tiempo definidos la clasificación puede quedar más reducida. En este sentido, la denominación «advecciones de primer o segundo cuadrante con precipitaciones» engloba los tipos «este y noreste con lluvia»; o la de «cielos africanos» que agrupa a «altocumulus africanos», «frente africano»y «este o noreste con escasa humedad», entre otros casos (Cuadro 2).

Respecto a las principales características éstas vienen reflejadas de forma muy sucinta en el Cuadro 2, por las razones ya aludidas. En el mismo (Cuadro 2) también se refleja una clasificación entre tipos de tiempo proclives (en sombreado) y no proclives al desarrollo de precipitaciones. 
CuAdro 2. Principales características de los tipos de tiempo definidos

\begin{tabular}{|c|c|}
\hline Tipos de tiempo & Características más relevantes \\
\hline $\begin{array}{l}\text { Advecciones del primer y segundo } \\
\text { cuadrante con precipitaciones }\end{array}$ & $\begin{array}{l}\text { - Clásico tipo de tiempo asociado a las } \\
\text { precipitaciones más abundantes en la zona. } \\
\text { Distinción de dos tipos: advecciones de } \\
\text { gregal (gran dicotomia pluviométrica } M a \text { - } \\
\text { rina alta y Baixa) y levante. } \\
\text { - Contexto sinóptico dominante: vagua- } \\
\text { das o depresiones frías de influjo directo } \\
\text { en el seno del sector delantero de las mis- } \\
\text { mas }(53,99 \%) \text {. }\end{array}$ \\
\hline Cielos «africanos» & $\begin{array}{l}\text { - Dos tipos básicos según abundancia de } \\
\text { nubosidad: altocumulus africanos y frente } \\
\text { africano (el de mayor grado de cobertura } \\
\text { nubosa), amén de otra variante de tempe- } \\
\text { rie que muestra especial vocación estival } \\
\text { clasificada como este o noreste con escasa } \\
\text { humedad relativa. } \\
\text { La principal característica de este tipo de } \\
\text { tiempo es la presencia de calima alta y, en } \\
\text { ocasiones, las precipitaciones de fango. } \\
\text { - Contexto sinóptico dominante: masas } \\
\text { de aire tropical continental de raigambre } \\
\text { mediterránea }(64,71 \% \text { ). }\end{array}$ \\
\hline Despejado o casi despejado & $\begin{array}{l}\text { - El tipo de tiempo más frecuente }(25,85 \% \\
\text { de } 1262 \text { casos }) \text {. } \\
\text { - Contexto sinóptico dominante: masas } \\
\text { de aire de origen subtropical }(61,33 \%) \text {. }\end{array}$ \\
\hline Este sin lluvia o escasa precipitación & $\begin{array}{l}\text { - Gran contraste de nubosidad entre lito- } \\
\text { ral y relieves. En ocasiones montera en } \\
\text { Serra Gelada (Vid Mapa 1, pag. } 13 \text { ). } \\
\text { - Contexto sinóptico dominante: masas } \\
\text { de origen subtropical }(54,24 \%) \text {. }\end{array}$ \\
\hline Frente frío activo & $\begin{array}{l}\text { - Presencia de nieblas prefrontales o fron- } \\
\text { tales, tanto en el caso de frentes activos o } \\
\text { no activos (previamente en el } 42,98 \% \text { de } \\
\text { las ocasiones y, durante el paso de la dis- } \\
\text { continuidad frontal en el } 57,02 \%) \text {. } \\
\text { - Contexto sinóptico dominante: masas } \\
\text { de aire de origen polar en el } 88,68 \% \text {, prin- } \\
\text { cipalmente valles planetarios con eje al oes- } \\
\text { te del litoral mediterráneo }(60,38 \%) \text {. }\end{array}$ \\
\hline
\end{tabular}




\begin{tabular}{|c|c|}
\hline Frente poco activo & $\begin{array}{l}\text { - Nubosidad media y alta de escasas re- } \\
\text { flectividades en el canal visible (normal- } \\
\text { mente catafrentes fríos). } \\
\text { - Contexto sinóptico dominante: masas } \\
\text { de aire de origen polar }(66 \%) \text {, con domi- } \\
\text { nio de las circulaciones zonales }(27,47 \%) \text {. }\end{array}$ \\
\hline Niebla o niebla alta & $\begin{array}{l}\text { - Dos tipos básicos: el invernal o equi- } \\
\text { noccial (niebla o niebla alta, Foto } 1 \text { ) y otro } \\
\text { estival más frecuente (niebla alta noctur- } \\
\text { na, en ocasiones fracturada). } \\
\text { - Contexto sinóptico dominante para las } \\
\text { nieblas altas nocturnas: masas de origen } \\
\text { subtropical }(66,67 \%) \text {, especialmente las } \\
\text { centradas en el litoral mediterráneo o con } \\
\text { eje en el mediterráneo occidental. }\end{array}$ \\
\hline Noreste sin lluvia o escasa precipitación & $\begin{array}{l}\text { - Formaciones nubosas orográficas que } \\
\text { dotan de personalidad a la comarca: Capu- } \\
\text { cha en Puig Campana y muro de Foehn en } \\
\text { Aitana, Aixortà, Carrascal de Parcent o } \\
\text { Bèrnia (Vid. Mapa 1, pag. 13). } \\
\text { - Contexto sinóptico dominante: masas } \\
\text { de origen polar }(67,31 \%) \text {, con dominio del } \\
\text { influjo marginal de ondas baroclínicas } \\
(40,38 \%) \text {. }\end{array}$ \\
\hline Nubes de evolución con escasa humedad & $\begin{array}{l}\text { - Gran dicotomía entre mar y tierra (con } \\
\text { nubes de desarrollo vertical harto más pro- } \\
\text { nunciado en el segundo medio). } \\
\text { - Contexto sinóptico dominante: ondas } \\
\text { baroclínicas con eje centrado en el litoral } \\
\text { mediterráneo o mediterráneo occidental con } \\
\text { sectores descendentes que afectan de lleno } \\
\text { a la zona }(45 \%) \text {. }\end{array}$ \\
\hline Nubes de evolución en interior & $\begin{array}{l}\text { - Dos tipos básicos en función del grado } \\
\text { de nubosidad: sólo de tipo alto sin men- } \\
\text { guar prácticamente la insolación y, el pro- } \\
\text { totípico, ligado a nubosidad de tipo medio } \\
\text { que reduce la insolación durante la segun- } \\
\text { da mitad de la tarde, en contadas ocasio- } \\
\text { nes con precipitación. } \\
\text { - Contexto sinóptico dominante: surcos } \\
\text { barométricos que proyectan su influjo de } \\
\text { forma indirecta, eso sí, en el seno del sec- } \\
\text { tor de mayor advección de vorticidad } \\
\text { ( } 31,03 \% \text {, para el tipo de mayor nubosidad } \\
\text { sin precipitación). }\end{array}$ \\
\hline
\end{tabular}




\begin{tabular}{|c|c|}
\hline Nubosidad acumulada por brisa & $\begin{array}{l}\text { - Formaciones nubosas de retención y/o } \\
\text { orográficas que, asimismo, constituyen uno } \\
\text { más de los atributos que conforman el } \\
\text { paisaje de la comarca de la Marina Baixa: } \\
\text { monteras sobre Bèrnia, Puig-Ponoig, Se- } \\
\text { rra Gelada e incluso capuchas en Penyal } \\
\text { d'Ifac y nieblas de ladera en Bèrnia, Puig- } \\
\text { Ponoig, etc (Vid. Mapa } 1 \text { pag. 13). } \\
\text { - Contexto sinóptico dominante: masas } \\
\text { de origen subtropical }(57 \%) \text {. }\end{array}$ \\
\hline $\begin{array}{l}\text { Nubosidad de evolución diurna con } \\
\text { precipitaciones generalizadas }\end{array}$ & $\begin{array}{l}\text { - Participación más o menos activa de } \\
\text { los «nidos» termo-convectivos de las sie- } \\
\text { rras prelitorales: Aitana, Puig-Ponoig o } \\
\text { Bèrnia (Vid Mapa 1, pag. 13). El sector } \\
\text { costero no se suele ver muy «beneficiado» } \\
\text { por las precipitaciones dado los flujos pre- } \\
\text { dominantes en la media y alta troposfera y } \\
\text { las áreas que constituyen el origen de los } \\
\text { núcleos termo-convectivos. } \\
\text { - Contexto sinóptico dominante: domi- } \\
\text { nio de las masas de aire de origen polar } \\
(78,72 \%)\end{array}$ \\
\hline Nubosidad media y alta a sotavento & $\begin{array}{l}\text { - Nubosidad de tipo medio y alto a sota- } \\
\text { vento que puede reducir la insolación de } \\
\text { forma considerable, en ocasiones con for- } \\
\text { maciones lenticulares espectaculares. } \\
\text { - Contexto sinóptico dominante: masas } \\
\text { de origen polar }(83,33 \%) \text {, principalmente } \\
\text { vaguadas centradas en el litoral mediterrá- } \\
\text { neo o el mediterráneo occidental }(47,37 \%) \text {. }\end{array}$ \\
\hline Ondas de stratocumulus & $\begin{array}{l}\text { - Stratocumulus la mayor parte de la ve- } \\
\text { ces con elevada insolación en el litoral. } \\
\text { - Contexto sinóptico dominante: masas } \\
\text { de origen polar }(91,11 \%) \text {, especialmente } \\
\text { circulaciones zonales }(41,67 \%) \text {. }\end{array}$ \\
\hline
\end{tabular}

Elaboración propia.

\subsection{Variación estacional de los tipos de tiempo}

En primer lugar, cabe mencionar que los resultados expuestos a continuación, dado el exiguo periodo analizado, sólo pueden pretender ser generales y aproximativos, en ningún modo concretos o excluyentes, sino cualitativos. No obstante, ello no es óbice para que carezcan de interés.

Latitud, longitud, solar peninsular y continente africano, con sus respectivos relieves, y la presencia de un mar cuasi continental junto con la migración estacional de los centros de 
acción, en función del Mecanismo Cósmico de las Estaciones, determinan el clima del área objeto de estudio y su variabilidad intranual e interanual, y, por tanto, las variaciones estacionales presentes en cualquiera de las variables que conforman la abstracción climática, así como la realidad meteorológica.

De esta forma, tras el periodo estival las condiciones atmosféricas suelen resultar más inestables, fruto del descenso latitudinal de la subsidencia subtropical y, por ello, más proclives para el desencadenamiento de precipitaciones y tipos de tiempo deudores de una circulación atmosférica más intensa. En efecto, así lo reflejan los porcentajes de las temperies correspondientes a advecciones marítimas con precipitación (surestes, levantes y gregales), frentes fríos activos y nubes de desarrollo vertical con precipitación, cuestión que, asimismo, se manifiesta en otras situaciones atmosféricas estables, típicamente invernales (nubosidad orográfica de sotavento), como, también, en otros meteoros como la visibilidad.

Además, ya no en relación al mayor dinamismo atmosférico de los «westerlines» sino a factores de índole térmica, la presencia de nieblas y precipitación horizontal oculta en estado líquido también han manifestado esta vocación equinoccial o invernal (Vid. Cuadro 2).

Asimismo, una característica que conviene resaltar es la mayor idoneidad de los periodos paroximales (otoño y primavera) para que las condiciones atmosféricas resulten más adecuadas para el desarrollo de precipitaciones, y ello, por factores de raigambre dinámica, como ya se ha indicado previamente, pero también de carácter térmico.

En relación a este último aspecto, es menester encarecer, por reiterativo que resulte, el papel jugado por el mar mediterráneo en las precitaciones recogidas durante los episodios caracterizados por advecciones de primer o segundo cuadrante.

Por otro lado, otros dos tipos de tiempo también han manifestado una mayor recurrencia a favor de factores de índole térmica, bandas nubosas configuradas en torno a una borrasca de estructura frontal y nubes de desarrollo vertical con precipitaciones generalizadas.

Respecto al primer caso, si bien el mayor dinamismo del vórtice circumpolar al final del otoño y parte del periodo invernal y principios del equinoccio de primavera explica la elevada frecuencia en el que las discontinuidades frontales han afectado a Benidorm durante este margen temporal ${ }^{22}$, se manifiesta un mínimo secundario invernal en la influencia de superficies frontales probablemente ligado a la mayor potencia y frecuencia del anticiclón térmico centroeuropeo y su apófisis Ibérica, que imponen un eficaz abrigo aerológico durante este periodo, especialmente durante el mes de febrero, obligando a las borrascas del «frente polar» a desviar sus trayectorias hacia otras latitudes permaneciendo la Península Ibérica al margen de su influencia.

En relación a la segunda situación, señalar que el desarrollo de precipitaciones termoconvectivas de distribución general durante el periodo «frío» del año, a pesar de que la frecuencia de atmósferas baroclínicas resulta mayor, como éstas no acostumbran a ir ligadas a desarrollos convectivos sino al paso de bandas frontales, no reúnen las condiciones adecuadas para el desarrollo de este tipo de tiempo. Incluso, cuando la inestabilidad no resulta muy acusada, y el cielo aparece con menor grado de cobertura nubosa, los registros térmicos no suelen alcanzar valores lo suficientemente elevados como para generar ascensos importantes. De otro lado, a este mismo respecto, en verano reina la estabilidad, y con mucha menor frecuencia la inestabilidad relativa, por lo que el desarrollo de nubosidad

22 Aunque la mayor parte de las ocasiones suelen corresponderse con bandas nubosas de escasa actividad. 


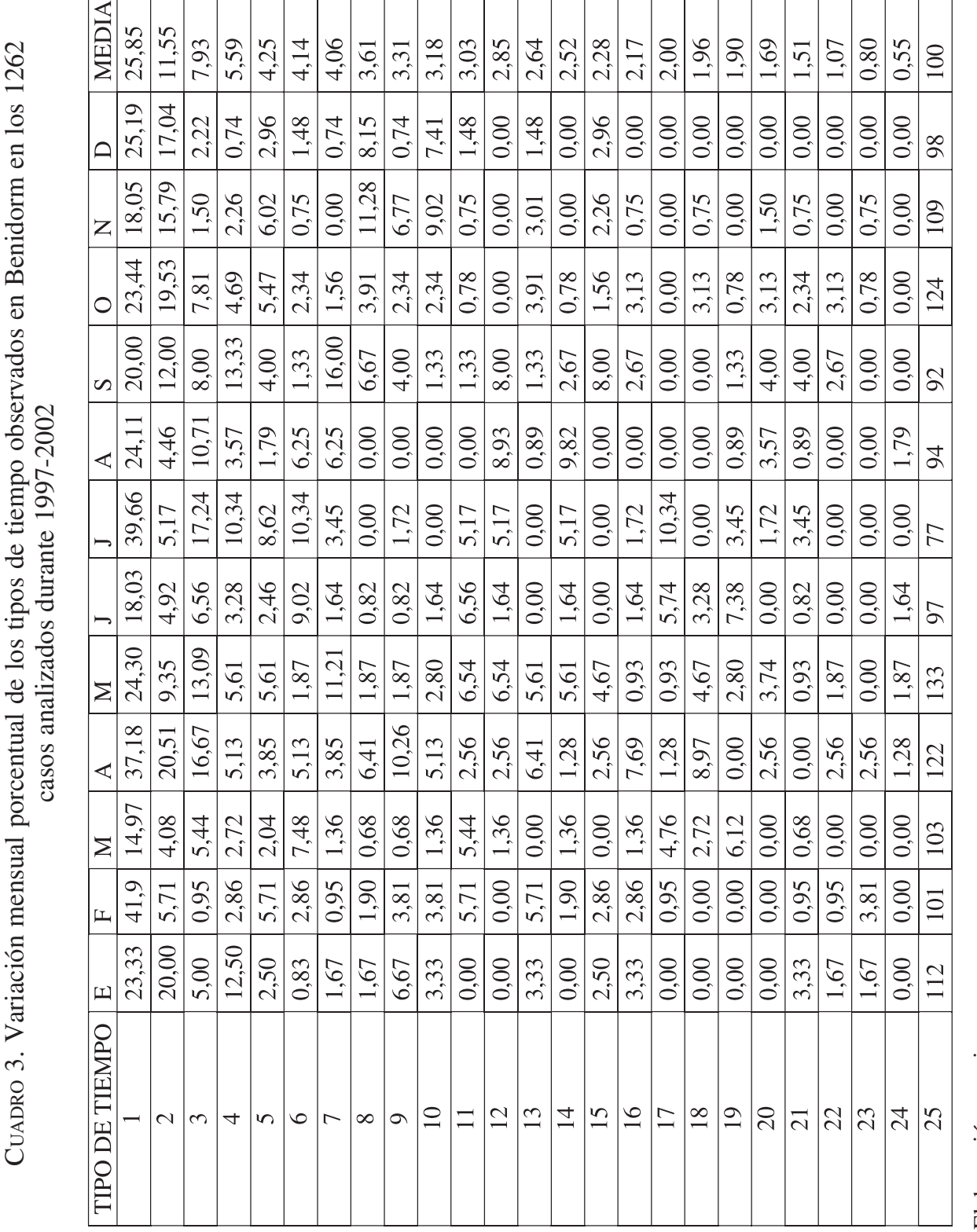


vertical precisa de importantes exageraciones de gradiente para generar movimientos verticales de aire capaces de romper el nivel de inversión impuesto por la subsidencia subtropical. De esta forma, durante el periodo estival, aún cuando exista humedad, principalmente en niveles bajos, no se llegan a generar cumulus de importancia en los relieves prelitorales. En cambio, en primavera y otoño, la recurrencia del tiempo inseguro se incrementa y, además, este estado atmosférico se acompaña de tensiones de vapor de agua y registros térmicos adecuados. Ambos favorecen el desarrollo de movimientos ascendentes en los relieves prelitorales capaces de derivar en la formación núcleos termoconvectivos que afecten al litoral.

Asimismo, existen otros tipos de tiempo típicamente veraniegos, como, por ejemplo, los calificados como «africanos» y los ligados a nieblas altas o stratus «nocturnos», que devienen, especialmente, de temperies impuestas por crestas mediterráneas.

Por último, mencionar que aparece un tipo de tiempo de transición, entre el periodo canicular y las estaciones equinocciales, concretamente el ligado a la influencia nubosa de desarrollos convectivos generados en zonas de interior de las provincias de Alicante o Valencia, e incluso de la de Murcia y Albacete, que, durante el periodo analizado, se ha presentado preferentemente durante la segunda mitad de la primavera y verano y principios de verano y otoño.

\section{Conclusiones}

A modo de conclusión, podríamos señalar que la temperie en Benidorm durante el periodo de tiempo analizado ha manifestado, a grandes rasgos, las características propias de su localización en relación con la Circulación Atmosférica General y las matizaciones que introducen los factores geográficos. Por ello, entre las temperies observadas con mayor frecuencia se encuentran aquellas en las que el sol resultó ser el máximo exponente meteorológico, el influjo de bandas nubosas poco activas estructuradas en torno a borrascas «noruegas» y atmósferas «calmas» con desarrollo de vientos «térmicos» y acumulación de nubosidad en los relieves.

En definitiva, el clima local de Benidorm no es sino de transición hacia el sector más árido de la región natural del SE ibérico ${ }^{23}$, y, sin considerar las influencias urbanas, denota una evidente protección pluviométrica, así como un socaire respecto a los flujos del tercer cuadrante y los temporales marítimos meteorológicos y sus afecciones, fundamentalmente respecto a aquellos que presentan una componente noreste, no así en su temperatura, al menos en el grado que algunos autores han señalado, evidentemente, en relación con su entorno inmediato.

\section{Bibliografía}

ALMIÑANA OROZCO, P. (2001): Els topònims de Benidorm: (1321-1955). Ayuntamiento de Benidorm. Alicante, $373 \mathrm{pp}$.

BARRY, R. y CHORLEY, R. (1999): Atmósfera, tiempo y clima. (7ed.). Ediciones Omega. Barcelona, $441 \mathrm{pp}$.

BESANCENOT, J.P. (1991): Clima y turismo. Massom, Barcelona, 223 pp.

23 Quereda Sala calculó una media de precipitación de 344,4 mm. a través de extrapolaciones realizadas con los datos registrados en Benidorm durante el periodo 1954-68 considerando como referencia la información recogida en el observatorio meteorológico de Alicante entre 1943 y 1968. 
BRIMACOMBE, C.A. (1991): Atlas de imágenes meteosat. Instituto Nacional de Meteorología, Madrid, $492 \mathrm{pp}$.

DORTA ANTEQUERA, P. (1996): «Las inversiones térmicas en Canarias», en Investigaciones Geográficas, nº15, Instituto Universitario de Geografía, Universidad de Alicante, pp. 109-123.

ESCRIG BARBERÁ, J., MONTÓN CHIVA, E. y QUEREDA SALA, J. (2000): «La evolución de las precipitaciones en la cuenca occidental del mediterráneo», en Investigaciones Geográficas, ${ }^{\circ}$ 24, Instituto Universitario de Geografía, Universidad de Alicante, Alicante, pp. 17-35.

ESCRIG BARBERÁ, J., MONTÓN CHIVA, E. y QUEREDA SALA, J. (2002): «Las interacciones atmósfera-mar en la climatología mediterránea del 2001», en Investigaciones Geográficas, nº 29 , Instituto Universitario de Geografía, Universidad de Alicante, Alicante, pp. 23-38.

FONT TULLOT, I. (2000): Climatología de España y Portugal (2 $2^{\mathrm{a}}$ ed.). Ediciones de la Universidad de Salamanca. Salamanca, 422 pp.

GIL OLCINA, A. y OLCINA CANTOS, J. (1997): Climatología General. Ediciones Ariel. Barcelona, 579 pp.

GÓMEZ MARTÍN, B. (1999): «La relación clima-turismo: consideraciones básicas en los fundamentos teóricos y prácticos», en Investigaciones Geográficas, nº 21, Instituto Universitario de Geografía, Universidad de Alicante, Alicante, pp. 21-33.

MARTÍN VIDE, J., GRIMALT GELABERT, M. y MAURI, F. (1996): Guía de la Atmósfera. Previsión del tiempo a partir de la observación de la nubes. Ediciones el Mèdol. Tarragona, 168 pp.

MONTÓN CHIVA, E. y QUEREDA SALA, J. (1997): «Temporales de levante en la fachada mediterránea española: ¿sucesos imprevisibles?», en Investigaciones Geográficas, $\mathrm{n}^{\circ} 18$, Instituto Universitario de Geografía, Universidad de Alicante, Alicante, pp. 5-18.

MORALES RODRÍGUEZ, C. y ORTEGA VILLAZÁN, M.T. (1994): «Aproximación al estudio de las nieblas en el valle medio del Duero», en Investigaciones Geográficas, $\mathrm{n}^{\circ} 18$, Instituto Universitario de Geografía, Universidad de Alicante, Alicante, pp. 23-44.

O.M.M. (1993): Atlas Internacional de Nubes. Manual de observación de nubes y otros meteoros (Volumen I). Organización Meteorológica Mundial. Ginebra, 159 pp.

OLCINA CANTOS, J. (1994): Tormentas y granizadas en las tierras alicantinas. Publicaciones de la Universidad de Alicante. Instituto Universitario de Geografía. Alicante, 317 pp.

OLCINA CANTOS, J. y QUEREDA SALA, J. (1994): «Las lluvias de barro en la vertiente mediterránea de la Península Ibérica», en Investigaciones Geográficas, ${ }^{\circ}$ 12, Instituto Universitario de Geografía, Universidad de Alicante, Alicante, pp. 7-22.

QUEREDA SALA, J.J. (1978): Comarca de La Marina (Alicante). Estudio de Geografía Regional. Excelentísima Diputación Provincial de Alicante. Alicante, 431 pp.

RAMÓN MORTE, A. (1991): «Valoración de la tradición oral como fuente en el estudio de nubes y tipos de tiempo», en Investigaciones Geográficas, $\mathrm{n}^{\circ}$ 9, Instituto Universitario de Geografía, Universidad de Alicante, Alicante, pp. 115-127.

RAMÓN MORTE, A. (1992): Clima y tradición oral en Alicante. Instituto de Cultura Juan GilAlbert, Alicante, $286 \mathrm{pp}$.

RASILLA ÁLVAREZ, D. (2003): «Aplicación de un método de clasificación sinóptica a la península ibérica», en Investigaciones Geográficas, $n^{\circ} 30$, Instituto Universitario de Geografía, Universidad de Alicante, Alicante, pp. 27-45.

ROSELLÓ i VERGER, V.M. (1995): Geografía del País Valencià. Ediones Alfons el MagnàminIVEI. Valencia, $640 \mathrm{pp}$.

TOHARIA, M. (1985): Meteorología popular. Ediciones el Observatorio. Madrid, 125 pp.

VALLADARES BETHENCOURT, P. (1996): «Propuesta metodológica para el estudio del mar de nubes: el caso del año 1989 en el norte de Tenerife», en Investigaciones Geográficas, nº 15 , Instituto Universitario de Geografía, Universidad de Alicante, Alicante, pp. 99-108.

WEGE, K. (1993): El tiempo. Causas y fenómenos. Editorial Hispano Europea. Barcelona, 95 pp. 